\title{
In vitro digestibility and the characteristics of puffed products from different degrees of milling and moisture content of adlay grain (Coix lacryma-jobi L.)
}

\author{
Tensiska*, Cahyana, Y., Nurhadi, B., Desani, W.D. and Subroto, E. \\ Department of Food Industrial Technology, Faculty of Agro-Industrial Technology, Universitas \\ Padjadjaran, Jl.Raya Bandung-Sumedang Km. 21, Jatinangor, Sumedang 40600, Indonesia
}

\begin{abstract}
Article history:
Received: 29 September 2020

Received in revised form: 6

November 2020

Accepted: 1 January 2021

Available Online: 18 April

2021

Keywords:

Adlay,

Whole grain,

Polished,

Puffing,

In vitro digestibility

DOI:

https://doi.org/10.26656/fr.2017.5(2).548
\end{abstract}

\begin{abstract}
Adlay (Coix lacryma-jobi L.) is one of the cereals that can be developed into slowdigesting instant food. The degree of milling and moisture content of cereals can affect the digestibility of the food products. The purpose of this study was to determine the proper degree of milling and moisture content of adlay seeds so that a puffing product with high slowly digestible starch (SDS) content and organoleptic characteristics acceptable to the panelists was produced. This study used an experimental method consisting of two main treatments: the degree of milling (whole grain and polished) and the moisture content of adlay seeds $(10 \%, 13 \%, 16 \%$, and $19 \%)$. In vitro digestibility was measured by used pancreatic porcine $\alpha$-amylase. The results showed that puffed adlay with the highest SDS and organoleptic characteristics that were still acceptable to the panelists was puffed polished adlay with an initial moisture content of $13 \%$. The adlay puffed had SDS of about $35.98 \%$, hardness 2795.83 gf, degree of gelatinization $67.90 \%$, the moisture content of $5.94 \%$, and rehydration power of $59.40 \%$. The preferences for color, taste, aroma, and after-taste of adlay puffed were in the normal category while the texture was in the preferred category.
\end{abstract}

\section{Introduction}

Cereals are an important source of carbohydrates or starches and have been used as staple foods by most of the world's population. Based on the rate and extent of digestibility, starch is divided into three types, namely resistant starch (RS), slowly digestible starch (SDS), and rapidly digestible starch (RDS) (Englyst and Englyst, 2005). The RDS can be calculated from the amount of maltose released within one hour during the incubation period with $\alpha$-amylase at $37^{\circ} \mathrm{C}$. In contrast, SDS is calculated when the amount of maltose released after one hour at a certain time until there is no more significant increase in the amount of maltose. Furthermore, when there is no significant increase in maltose, it indicates that the remaining starch is resistant (RS) (Guraya et al., 2001; Cahyana et al., 2019). The increase in diabetes and the need for a stable supply of glucose for a long time has led to an increased demand for products containing high SDS. Consumption of SDS will not cause a rapid increase in blood glucose, so it is suitable for people with diabetes mellitus (Zhang and Hamaker, 2009).

The digestibility of starch can be slowed down by non-starch components, especially protein, lipids, and dietary fiber. The formation of starch-protein and amylose-lipid complexes can reduce the digestibility of starch. The digestibility of starch is affected by protein, even in small amounts in cereals (Ezeogu et al., 2008). Starch-protein complex can reduce the rate of amylolysis in cereals, while the amylose-lipid complex causes the starch to become resistant to digestive enzymes (Biliaderis, 1991; Jaspreet et al., 2010). In an in vitro model, it was observed that the enzymatic digestion of starch in the amylose-lipid complex was slower (Cui and Oates, 1999). Dietary fiber also decreases the digestibility rate of starch when it forms a physical barrier to limit hydrolytic enzyme access to starch (Snow and O'Dea, 1981; Grundy et al., 2016).

Adlay is one of the minor cereals that have the potential to be developed into slow-digesting food because it contains carbohydrates (65-68\%) and other components which are relatively high compared to other cereals, namely protein $(9.8-15.6 \%)$ and fat $(5-9 \%)(\mathrm{Wu}$ et al., 2007; Yang et al., 2008; Tensiska et al., 2017). Besides, the dietary fiber from the adlay can be maintained by milling without polished, which is called whole grains. Whole grains are the intact, ground, cracked or flaked caryopsis, whose principal anatomical 
components, the starchy endosperm, germ, and bran, are present in substantially the same relative proportions as they exist in the intact caryopsis' (Slavin, 2004). Whole grain adlay contains $12.5 \%$ dietary fiber, while the dietary fiber in polished grains is about $9.9 \%$ (Tensiska et al., 2017). The use of whole grains in bread or pasta making where the cell layer surrounding the starch granules is still intact can act as a physical barrier to enzyme access, allowing for increased SDS content (Miao et al., 2015). An increase in the proportion of insoluble dietary fiber (IDF) in cake making causes an increase in SDS and decreases RDS (Oh et al., 2014).

Increasing people's consumption of adlay can be done by processing it into instant food, one of which is the puffing method. Puffing is processing using high temperature and pressure then the product is released suddenly so that volume expansion occurs and a porous structure is formed. In the puffing process, perfect starch gelatinization occurs, resulting in a product that is easily digested. Processing cereals using the puffing method can improve physical properties, increase the degree of gelatinization, and increase the digestibility of cereals (Huang et al., 2018). Therefore, reducing digestibility can be conducted by limiting the starch gelatinization by altering the raw material's moisture content. The degree of gelatinization positively correlates with the rate of hydrolysis of starch by $\alpha$-amylase in vitro (Holm et al., 1988; Dhital et al., 2017; Subroto et al., 2019). Research by Chung et al. (2006), with partial gelatinization treatment of glutinous rice starch, showed that SDS production increased while RDS decreased compared to fully gelatinized starch. Meanwhile, research about adlay starch showed that SDS of native adlay starch was higher $(20.6 \pm 1.7 \%)$ than maize starch $(15.2 \pm 1.8 \%)$ and potato starch $(9.6 \pm 0.7 \%)$ (Chen et al., 2019) so that adlay have potency as instant food with high SDS which useful for people with diabetes.

The purpose of this study was to produce instant food products from adlay that had the highest SDS content and were organoleptically acceptable from different degrees of milling and limiting the moisture content of adlay grain as raw material for puffed products.

\section{Materials and methods}

\subsection{Materials}

The material of this research was adlay (Coix lacryma-jobi L.) of local varieties which was planted in Sumedang, West Java, Indonesia. Pancreatic porcine $\alpha$ amylase Type IV-B was purchased from Sigma-Aldrich Co., Ltd. All chemical reagents were of analytical grade and used directly without further purification.

\subsection{Preparation adlay grain for puffing}

The study consisted of two types of treatment, namely the degree of milling (whole grain and polished) and moisture content of adlay grain $(10 \%, 13 \%, 16 \%$, and $19 \%$ ) so that 8 treatment combinations were repeated 3 times. Determination of the amount of water needed to adjust the content of raw materials by measuring the initial moisture content of adlay grain. The adjustment of moisture content was conducted by spraying aquadest gradually on the adlay grain and at the same time was homogenized by mixing. The next step was balancing the moisture content by wrapping the adlay grains in aluminium foil and stored at $4^{\circ} \mathrm{C}$ for $24 \mathrm{hrs}$. Finally, the samples were tested for ensuring their moisture content appropriate with each treatment.

\subsection{Puffed adlay processing}

The puffing process is conducted using an explosive puffed maker (Koica, South Korea). The samples of adlay whole grain and polished grain previously adjusted for moisture content were put into a puffing maker with a temperature of $250 \pm 5^{\circ} \mathrm{C}$ with a retention time of 7 seconds. This condition was obtained by trial and error for the best development of the puffing product.

\subsection{Determination of the degree of gelatinization}

The determination of the degree of gelatinization followed Nurdjanah et al. (2017). The sample (5 g) was heated in $100 \mathrm{~mL}$ of aquadest, then took $0.5 \mathrm{~g}$ of the solution and added $35 \mathrm{~mL}$ of aquadest. This mixture was then stirred for 30 mins, then $2.5 \mathrm{~mL}$ of $\mathrm{KOH} 0.2 \mathrm{~N}$ was added, then filtered. $0.5 \mathrm{~mL}$ sample was taken into a test tube then add $0.5 \mathrm{~mL}$ of $\mathrm{HCl} 0.5 \mathrm{~N}, 0.1 \mathrm{~mL}$ of iodine, and $8.9 \mathrm{~mL}$ of aquadest. The reaction mixture was shaken then measured for absorbance at $574.5 \mathrm{~nm}$. The degree of gelatinization was measured by standard curves with various levels of gelatinization of $20 \%, 40 \%$, $60 \%, 80 \%$, and $100 \%$.

\subsection{Determination of starch digestibility in vitro}

Measurement of starch digestibility in vitro was carried out by calculating the amount of maltose released through the breakdown of starch using the porcine $\alpha$ amylase and measuring the absorbance at a wavelength of $540 \mathrm{~nm}$ (Guraya et al., 2001). Approximately $1 \mathrm{~g}$ of VI-B $\alpha$-amylase from pancreatic porcine was dissolved in $100 \mathrm{~mL}$ of $0.9 \% \mathrm{NaCl}$. Next, a $1 \%$ DNSA solution was made by dissolving $1 \mathrm{~g}$ of DNS in $20 \mathrm{~mL}$ of $\mathrm{NaOH}$ $2 \mathrm{~N}$, then adding $50 \mathrm{~mL}$ of aquadest and $30 \mathrm{~g}$ of potassium sodium tartrate. Samples $(200 \mathrm{mg})$ were put into eight centrifuge tubes, then $15 \mathrm{~mL}$ phosphate buffer and $750 \mu \mathrm{L} \alpha$-amylase added, then incubated in a water 
bath for $28 \mathrm{hrs}$ with sampling every $1 \mathrm{hr}$. Approximately $500 \mu \mathrm{L}$ of the sample was put into a test tube containing $2 \mathrm{~mL}$ of DNSA, then heated in a water bath for $10 \mathrm{mins}$ and then cooled again. Approximately, $20 \mathrm{~mL}$ of aquadest was added, then filtered, and the absorbance was measured at $540 \mathrm{~nm}$. The result was expressed as mg of maltose produced by $\alpha$-amylase digestion. The concentration of maltose was measured by using a standard curve of maltose.

\subsection{Determination of rehydration power}

The rehydration power shows the ability of the sample to absorb liquid when soaked for 1-1.5 mins. The absorption test can be determined by weighing $1 \mathrm{~g}$ of sample, taken randomly, then immersed in water for 1 min. The ratio between sample and water was 1: 2 . The soaked sample was then taken and drained, then weighed (Abrol et al., 2014).

\subsection{Hedonic test}

The hedonic test of the puffed product involved fifteen semi-trained panelists. The panelists were the students undergraduate of food technology department whose passed the sensory analysis course and often be asked as panelist for the hedonic test of food. The assessment was carried out on color, flavor, crunchiness, taste, texture, and after-taste. The assessment used the scales of 1 to 5 , which 1: dislikes very much, 2: dislikes, 3: normal, 4: likes, 5: likes very much.

\subsection{Statistical analysis}

One-way analysis of variance (ANOVA) was performed with Duncan's multiple range test $\left({ }^{*} p<0.05\right)$ using SPSS ( 20.0 version, IBM). The significance level was set as $* \mathrm{p}<0.05$.

\section{Results and discussion}

\subsection{Degree of gelatinization}

Based on Table 1, the initial moisture content had a significantly different effect on the gelatinization degree of puffed adlay at the two degrees of milling. The degree of gelatinization in the two types of milling degrees increased with increasing moisture content of adlay grain. The initial moisture content of the material significantly affects the gelatinization process. The greater the material's initial moisture content, the more likely it is that the gelatinization process will occur completely. This was shown in the treatment of polished grain with $16 \%$ and $19 \%$ moisture content, which resulted in a significantly higher degree of gelatinization than $10 \%$ and $13 \%$.

During the puffing, the moisture contains in the grain causes the gelatinization of starch, namely, the amylopectin helix opens and forms an amorphous gel. Water that is absorbed in amorphous areas causes the starch granules to lose their crystalline structural stability (Ratnayake and Jackson, 2006). The higher moisture content of the grain will cause more amylose to come out of the starch granules so that the degree of gelatinization is higher. The lower the initial moisture content of the grain resulted in a low gelatinization degree. The gelatinization process was not complete due to the lack of water. Starch gelatinization requires excess water so that the starch intermolecular bonds (hydrogen bonds) can be broken (Daomukda et al., 2011).

Table 1 also shows that the degree of milling significantly affected the degree of gelatinization of the adlay grain at various initial moisture content. The degree of gelatinization of polished puffed adlay was higher than whole grains puffed. Whole grains contain bran (cellulose) which is difficult to bind to water molecules (Izydorczyk, 2005) so that the degree of starch gelatinization is lower.

\subsection{Digestibility of starch}

Based on Table 2, the difference in the initial moisture content of adlay grain has a significantly different effect on the SDS amount of puffed adlay at both degrees of milling. This can be seen from the decrease in the SDS value in each type of milling degree, along with the increase in the grain's initial moisture content. The greater the moisture of the grain, the higher the amount of water available for the gelatinization process so that the degree of gelatinization is higher. Gelatinized starch makes it easy for the $\alpha$-amylase to hydrolyze the $\alpha-(1,4)$ glycosidic bonds so that digestibility increases. In the grain with low moisture content, the gelatinization process only occurs partially or is incomplete (Roder et al., 2005), thereby reducing the hydrolysis of starch by the $\alpha$-amylase (Tester and

Table 1. Effect of interaction of degree of milling and moisture content of adlay grain on the degree of gelatinization (\%) of puffed adlay

\begin{tabular}{ccccc}
\hline \multirow{2}{*}{ Degree of Milling } & \multicolumn{4}{c}{ Moisture Content of Adlay Grain } \\
\cline { 2 - 5 } & $10 \%$ & $13 \%$ & $16 \%$ & $19 \%$ \\
\hline Polished Grain & $57.11 \pm 1.9^{\mathrm{a}, \mathrm{C}}$ & $67.9 \pm 1.2^{\mathrm{a}, \mathrm{B}}$ & $82.76 \pm 0.6^{\mathrm{a}, \mathrm{A}}$ & $96.46 \pm 2.6^{\mathrm{a}, \mathrm{A}}$ \\
Whole Grain & $13.86 \pm 1.2^{\mathrm{b}, \mathrm{D}}$ & $57.43 \pm 0.6^{\mathrm{b}, \mathrm{C}}$ & $78.17 \pm 1.0^{\mathrm{b}, \mathrm{B}}$ & $95.62 \pm 1.2^{\mathrm{a}, \mathrm{A}}$ \\
\hline
\end{tabular}

Values are expressed as mean \pm standard deviation. Values with the same lowercase superscript within the same column and the same uppercase superscript within the same row are not significantly different at $5 \%$ level. 
Table 2. Effect of interaction of degree of milling and moisture content of adlay grain on SDS content (\%) of puffed adlay

\begin{tabular}{ccccc}
\hline \multirow{2}{*}{ Degree of Milling } & \multicolumn{4}{c}{ Moisture Content of Adlay Grain } \\
\cline { 2 - 5 } & $10 \%$ & $13 \%$ & $16 \%$ & $19 \%$ \\
\hline Polished Grain & $40.29 \pm 0.3^{\mathrm{a} . \mathrm{A}}$ & $35.98 \pm 1.7^{\mathrm{a} . \mathrm{A}}$ & $30.25 \pm 5.1^{\mathrm{b} . \mathrm{B}}$ & $28.05 \pm 2.4^{\mathrm{b} . \mathrm{B}}$ \\
Whole Grain & $40.71 \pm 3.4^{\mathrm{a} . \mathrm{A}}$ & $36.88 \pm 0.1^{\mathrm{a} . \mathrm{AB}}$ & $35.02 \pm 3.2^{\mathrm{a} . \mathrm{B}}$ & $33.10 \pm 4.9^{\mathrm{a} . \mathrm{B}}$ \\
\hline
\end{tabular}

Values are expressed as mean \pm standard deviation. Values with the same lowercase superscript within the same column and the same uppercase superscript within the same row are not significantly different at $5 \%$ level.

Sommerville, 2003). The starch that was only partially gelatinized caused the starch to digest more slowly, indicated by the higher amount of SDS.

Table 2 also shows that the degree of milling has no significant effect on the SDS content at $10 \%$ and $13 \%$ moisture content, but significantly different for puffed with $16 \%$ and $19 \%$ moisture content. Puffed whole grains have a fairly high fiber content. Based on the research of (Tensiska et al., 2017), the content of dietary fiber in the adlay of whole grains is $12.53 \%$ while in the polished adlay was $9.95 \%$. The content of water-soluble fiber, such as pectin; and insoluble water, such as cellulose and hemicellulose in cereals, can affect the gelatinization process in puffed products (Altan et al., 2009). The presence of fiber or bran inhibits starch gelatinization and can also coat the starch granules, thus slowing the penetration of the $\alpha$-amylase .

The digestibility of starch can also be seen from the amount of RDS produced. Guraya et al. (2001) stated that the RDS content could be calculated from the amount of maltose released within one hour during the incubation period with $\alpha$-amylase at $37^{\circ} \mathrm{C}$. The results of statistical analysis showed that there was an effect of the interaction between the degree of milling and the grain's initial moisture content on the RDS value of the puffed adlay (Table 3).

Based on Table 3, at each degree of milling, the RDS value increases along with the increase in the moisture content of the material. Puffed adlay was produced by cooking using high temperature and pressure so that the proportion of starch with higher moisture content experienced greater gelatinization. The degree of milling resulted in significantly different RDS at the moisture content of $13 \%$ and $16 \%$. The presence of dietary fiber resulted in a relatively lower RDS. However, at a moisture content that was too low $(10 \%)$ or relatively high moisture content $(19 \%)$, the role of food fiber did not contribute to producing RDS

When there is no more increase in the amount of maltose released, it indicates that the starch is already resistant (Guraya et al., 2001). However, in this study, the stationary phase began to be reached in about 4 hours. The amount of maltose released can be seen in Figure 1. The amount of maltose released from the digestibility of puffed adlay averaged between 258-538 mg for $0-28 \mathrm{hrs}$.

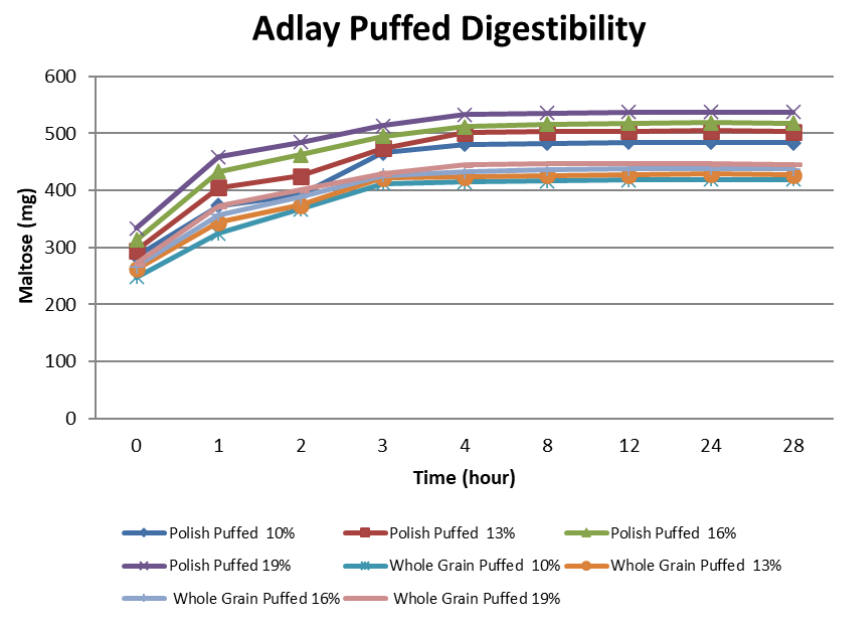

Figure 1. Total maltose released during incubation with $\alpha$ amylase

\subsection{Moisture content}

The initial moisture content of the material had a significantly different effect on the moisture content of the puffed adlay for the two types of milling degrees (Table 4). The higher the water content of adlay seeds resulted in the higher moisture content of puffed seeds in adlay polished and whole grains.

Besides, water can come from the environment when the puffed is cooled before packaging because the puffed adlay is hygroscopic. Puffed with a higher moisture content undergoes perfect development, resulting in a larger surface area and higher porosity so that the

Table 3. Effect of interaction of degree of milling and moisture content of adlay grain on RDS content (\%) of puffed adlay

\begin{tabular}{ccccc}
\hline \multirow{2}{*}{ Degree of Milling } & \multicolumn{4}{c}{ Moisture Content of Adlay Grain } \\
\cline { 2 - 5 } & $10 \%$ & $13 \%$ & $16 \%$ & $19 \%$ \\
\hline Polished Grain & $32.76^{\mathrm{a}, \mathrm{C}}$ & $40.42^{\mathrm{a}, \mathrm{B}}$ & $43.84^{\mathrm{a}, \mathrm{AB}}$ & $45.80^{\mathrm{a}, \mathrm{A}}$ \\
Whole Grain & $34.06^{\mathrm{a}, \mathrm{C}}$ & $36.73^{\mathrm{b}, \mathrm{BC}}$ & $39.89^{\mathrm{b}, \mathrm{B}}$ & $44.64^{\mathrm{a}, \mathrm{A}}$ \\
\hline
\end{tabular}

Means with the same lowercase superscript within the same column and the same uppercase superscript within the same row are not significantly different at 5\% level. 
Table 4. Effect of interaction of degree of milling and moisture content of adlay grain on moisture content (\%) of puffed adlay

\begin{tabular}{ccccc}
\hline \multirow{2}{*}{ Degree of Milling } & \multicolumn{4}{c}{ Moisture Content of Adlay Grain } \\
\cline { 2 - 5 } & $10 \%$ & $13 \%$ & $16 \%$ & $19 \%$ \\
\hline Polished Grain & $4.48 \pm 0.4^{\mathrm{a} . \mathrm{D}}$ & $5.94 \pm 0.3^{\mathrm{a} . \mathrm{C}}$ & $6.38 \pm 0.2^{\mathrm{a} . \mathrm{B}}$ & $7.39 \pm 0.4^{\mathrm{a} . \mathrm{A}}$ \\
Whole Grain & $4.59 \pm 0.5^{\mathrm{a} . \mathrm{D}}$ & $5.47 \pm 0.5^{\mathrm{a} . \mathrm{C}}$ & $6.44 \pm 0.7^{\mathrm{a} . \mathrm{B}}$ & $7.62 \pm 0.4^{\mathrm{a} . \mathrm{A}}$ \\
\hline
\end{tabular}

Values are expressed as mean \pm standard deviation. Values with the same lowercase superscript within the same column and the same uppercase superscript within the same row are not significantly different at $5 \%$ level.

product more hygroscopic. Table 4 also shows that the milling degree did not significantly affect the moisture content of the puffed adlay at various initial moisture content. High temperatures in the puffing process cause the product from the polish seeds and whole grains to release water together. The higher dietary fiber in whole grains cannot hold more water because it is classified as insoluble fiber found in bran.

\subsection{Rehydration power}

Rehydration power is the main parameter in determining product quality, where the higher the rehydration power, the better the quality of the cereal puff product. Puffed adlay has a high average value of rehydration power. Table 5 shows that the rehydration power was higher along with the high initial moisture content of the adlay seeds.

Rehydration power is affected by porosity. The greater the initial water content, the higher the gelatinization process, which causes the resulting puffed to expand so that the structure becomes more porous. The porous structure of the puffed has a broad absorption surface with larger pores, making it easier to absorb water (Marabi and Saguy, 2004). The average value of puffed polished's rehydration power is higher than the rehydration power of puffed whole grains. In puffed whole grains, the development power is lower because of the lower gelatinization rate, so the rehydration power was lower.

\subsection{Sensorial properties}

Based on Table 6, the highest color preference was adlay polished and whole grains with an initial moisture content of $19 \%$, while the lowest value came from adlay whole grains with an initial moisture content of $10 \%$. The seeds of adlay polished were creamy white, but they turned brownish-white when they undergo the puffing process. The colour change during the puffing process due to the expansion of the product's surface causes the color to fade, the caramelization reaction of carbohydrates, and the Maillard reaction (Lazou et al., 2010). The Maillard reactions produce a series of complex reactions initiated by the reaction between amines groups of protein with reducing sugars at high temperatures, then decompose and finally condense into insoluble brown pigments known as melanoidins (Rampersad et al., 2003). In the lower initial moisture content $(10 \%$ and $13 \%)$, the Maillard reaction proceeded well. It resulted in a darker brown color compared to puffed adlay with the initial moisture content of $16 \%$ and $19 \%$. The value of the color preference of the panelists increased when the higher moisture content and at polished adlay seeds.

The highest taste preference of the puffed adlay in the polished adlay treatment with an initial moisture content of $19 \%$ was included in the preferred category (Table 6). Puffed adlay has a distinctive tasteless adlay. The taste preferences increased as the adlay seed moisture content increased. Adlay seeds with sufficient moisture content have good puffing. When the seeds expand well, all of the seeds are fully ripe and give the distinctive flavor of ripe adlay seeds. Panelists prefer puffed polished taste compared to puffed whole grain. This is because the puffed polished does not contain bran like puffed whole grains, which causes a bitter taste.

The highest flavor preference of puffed adlay was found in polished and whole-grain adlay with the initial moisture content of $19 \%$, while the lowest value was in whole grain adlay with the initial moisture content of $10 \%$ (Table 6). The higher the water content of the raw material, the more perfect the development of the seeds is, and vice versa. The perfect puffed development produces a more fragrant flavor when compared to the thick puffed and imperfect cooking. Even though the puffed is hard, it still has a distinctive aroma, but also has a burnt smell. Adlay whole grains contain higher levels of fat from germ where the fat affects the aroma (Rapp et al., 2007). The presence of fat in food

Table 5. Effect of interaction of degree of milling and moisture content of adlay grain on rehydration power (\%) of puffed adlay

\begin{tabular}{ccccc}
\hline \multirow{2}{*}{ Degree of Milling } & \multicolumn{4}{c}{ Moisture Content of Adlay Grain } \\
\cline { 2 - 5 } & $10 \%$ & $13 \%$ & $16 \%$ & $19 \%$ \\
\hline Polished Grain & $43.75 \pm 1.0^{\mathrm{a}, \mathrm{D}}$ & $59.40 \pm 0.7^{\mathrm{a}, \mathrm{C}}$ & $76.87 \pm 0.3^{\mathrm{a}, \mathrm{B}}$ & $82.91 \pm 0.3^{\mathrm{a}, \mathrm{A}}$ \\
Whole Grain & $36.34 \pm 0.9^{\mathrm{b}, \mathrm{D}}$ & $47.73 \pm 0.4^{\mathrm{b}, \mathrm{C}}$ & $75.27 \pm 0.7^{\mathrm{b}, \mathrm{B}}$ & $78.87 \pm 0.4^{\mathrm{b}, \mathrm{A}}$ \\
\hline
\end{tabular}

Values are expressed as mean \pm standard deviation. Values with the same lowercase superscript within the same column and the same uppercase superscript within the same row are not significantly different at $5 \%$ level. 
Table 6. Effect of degree of milling and moisture content of adlay grain on sensorial properties of puffed adlay

\begin{tabular}{lccccc}
\hline \multicolumn{1}{c}{ Treatment } & Color & Taste & Flavor & Texture & After taste \\
\hline Puffed Polished 10\% & $1.73 \pm 0.70^{\mathrm{c}}$ & $1.80 \pm 0.68^{\mathrm{d}}$ & $3.80 \pm 0.56^{\mathrm{ab}}$ & $1.13 \pm 0.35^{\mathrm{e}}$ & $1.93 \pm 0.8^{\mathrm{c}}$ \\
Puffed Polished 13\% & $2.87 \pm 0.99^{\mathrm{b}}$ & $2.53 \pm 0.64^{\mathrm{b}}$ & $3.93 \pm 0.46^{\mathrm{ab}}$ & $3.27 \pm 0.70^{\mathrm{bc}}$ & $3.20 \pm 0.56^{\mathrm{a}}$ \\
Puffed Polished 16\% & $2.93 \pm 0.96^{\mathrm{b}}$ & $2.73 \pm 0.80^{\mathrm{b}}$ & $3.67 \pm 0.98^{\mathrm{ab}}$ & $3.07 \pm 1.03^{\mathrm{c}}$ & $2.53 \pm 0.83^{\mathrm{b}}$ \\
Puffed Polished 19\% & $3.87 \pm 0.74^{\mathrm{a}}$ & $3.67 \pm 0.98^{\mathrm{a}}$ & $4.13 \pm 0.64^{\mathrm{a}}$ & $4.27 \pm 0.59^{\mathrm{a}}$ & $3.53 \pm 0.64^{\mathrm{a}}$ \\
Puffed Whole Grain 10\% & $1.07 \pm 0.26^{\mathrm{d}}$ & $1.07 \pm 0.26^{\mathrm{e}}$ & $2.40 \pm 1.24^{\mathrm{c}}$ & $1.13 \pm 0.35^{\mathrm{e}}$ & $1.13 \pm 0.35^{\mathrm{d}}$ \\
Puffed Whole Grain 13\% & $1.87 \pm 0.52^{\mathrm{c}}$ & $1.93 \pm 0.46^{\mathrm{cd}}$ & $3.53 \pm 0.74^{\mathrm{ab}}$ & $2.40 \pm 0.51^{\mathrm{d}}$ & $2.07 \pm 0.8^{\mathrm{c}}$ \\
Puffed Whole Grain 16\% & $2.33 \pm 1.18^{\mathrm{bc}}$ & $2.33 \pm 0.82^{\mathrm{bc}}$ & $3.40 \pm 0.91^{\mathrm{b}}$ & $2.87 \pm 0.99^{\mathrm{cd}}$ & $2.00 \pm 0.65^{\mathrm{c}}$ \\
Puffed Whole Grain 19\% & $3.53 \pm 0.52^{\mathrm{a}}$ & $3.47 \pm 0.64^{\mathrm{a}}$ & $3.93 \pm 0.46^{\mathrm{ab}}$ & $3.60 \pm 0.63^{\mathrm{b}}$ & $3.47 \pm 0.64^{\mathrm{a}}$ \\
\hline
\end{tabular}

Values are expressed as mean \pm standard deviation. Values with the same lowercase superscript within the same column are not significantly different at 5\% level.

ingredients can increase the flavor of food but cannot cover the unpleasant smell of bran.

Based on Table 6 , the highest texture preference of puffed adlay was found in the polished adlay treatment with an initial moisture content of $19 \%$, while the lowest value was in the polished adlay and whole-grain treatment with an initial moisture content of $10 \%$. Adlay polished and whole grains with an initial moisture content of $10 \%$ produced the puffed products, which were tough due to low gelatinization. A well-developed puff produced a crunchier texture compared to the firm puffed. Water content was closely related to the crunchiness of the puffing product. Puffed with $19 \%$ moisture content has more air cavities (amorphous structure) resulting from the seed puffing process to produce a product with a higher level of crunch. The average texture preference of puffed from adlay polished is higher than the puffed from whole grains because the texture of puffed polished is more crispy. The higher insoluble fiber in puffed whole grains caused the texture to become tougher, less porous, and higher density.

The puffed adlay which was produced from polished seed with an initial moisture content of $19 \%$ has the highest after-taste preference. In comparison, the lowest value was the whole grain puffed adlay treatment with an initial moisture content of $10 \%$ (Table 6). The higher moisture content of adlay seeds, the higher after-taste preferences were found in puffed. Puffed adlay that expands well had a preferred flavor because it was cooked to perfection. Meanwhile, puffed with low water content, lack of puffing, causing unpleasant and bitter after-taste due to burnt. The average after-taste favorite value of puffed polished was higher than that of puffed whole grains. This was due to the puffed whole grains contained the bran, which has a bitter taste. The bitter taste will last longer in the mouth and cause a bad aftertaste.

\section{Conclusion}

Polished adlay with the seed moisture content of $13 \%$ produced puffed product with a high SDS content of $35.98 \%$ and had sensorial properties that were acceptable to the panelists. The puffed product had a hardness of $2795.83 \mathrm{gf}$, the degree of gelatinization about $67.90 \%$, moisture content of $5.94 \%$, and rehydration power of $59.40 \%$. The sensory properties of the product, namely the preference for colour, taste, aroma, and after-taste, were included in the normal category, while the texture was preferred by panelists.

\section{Conflict of interest}

The author declared no conflict of interest.

\section{Acknowledgments}

The authors would like to thank the Rector of Universitas Padjadjaran and the Ministry of Education and Culture of the Republic of Indonesia for the support provided.

\section{References}

Abrol, G.S., Vaidya, D., Sharma, A. and Sharma, S. (2014). Effect of solar drying on physico-chemical and antioxidant properties of mango, banana and papaya. National Academy Science Letters, 37, 5157. https://doi.org/10.1007/s40009-013-0196-1

Altan, A., McCarthy, K.L. and Maskan, M. (2009). Effect of extrusion cooking on functional properties and in vitro starch digestibility of barley-based extrudates from fruit and vegetable by-products. Journal of Food Science, 74(2), E77-E86.

Biliaderis, C.G. (1991). The structure and interactions of starch with food constituents. Canadian Journal of Physiology and Pharmacology, 69(1), 60-78. https:// doi.org/10.1139/y91-011

Cahyana, Y., Wijaya, E., Halimah, T.S., Marta, H., Suryadi, E. and Kurniati, D. (2019). The effect of different thermal modifications on slowly digestible starch and physicochemical properties of green 
banana flour (Musa acuminata colla). Food Chemistry, 274, 274-280. https://doi.org/10.1016/ j.foodchem.2018.09.004

Chen, J., Chen, Y., Ge, H., Wu, C., Pang, J. and Miao, S. (2019). Multi-scale structure, pasting and digestibility of adlay (Coixlachryma-jobi L.) seed starch. Food Hydrocolloids, 89, 885-891. https:// doi.org/10.1016/j.foodhyd.2018.11.050

Chung, H.-J., Lim, H.S. and Lim, S.-T. (2006). Effect of partial gelatinization and retrogradation on the enzymatic digestion of waxy rice starch. Journal of Cereal Science, 43(3), 353-359. https://doi.org/ https://doi.org/10.1016/j.jcs.2005.12.001

Cui, R. and Oates, C.G. (1999). The effect of amyloselipid complex formation on enzyme susceptibility of sago starch. Food Chemistry, 65(4), 417-425. https://doi.org/https://doi.org/10.1016/S0308-8146 (97)00174-X

Daomukda, N., Moongngarm, A., Payakapol, L. and Noisuwan, A. (2011). Effect of cooking methods on physicochemical properties of brown rice. 2nd International Conference on Environmental Science and Technology. Singapore: IACSIT Press.

Dhital, S., Warren, F.J., Butterworth, P.J., Ellis, P.R. and Gidley, M.J. (2017). Mechanisms of starch digestion by $\alpha$-amylase-Structural basis for kinetic properties. Critical Reviews in Food Science and Nutrition, 57(5), 875-892. https:// doi.org/10.1080/10408398.2014.922043

Englyst, K.N. and Englyst, H.N. (2005). Carbohydrate bioavailability. British Journal of Nutrition, 94(1), 1 -11. https://doi.org/DOI: 10.1079/BJN20051457

Ezeogu, L.I., Duodu, K.G., Emmambux, M.N. and Taylor, J.R.N. (2008). Influence of Cooking Conditions on the Protein Matrix of Sorghum and Maize Endosperm Flours. Cereal Chemistry, 85(3), 397-402. https://doi.org/10.1094/CCHEM-85-30397

Grundy, M.M.L., Edwards, C.H., Mackie, A.R., Gidley, M.J., Butterworth, P.J. and Ellis, P.R. (2016). Reevaluation of the mechanisms of dietary fibre and implications for macronutrient bioaccessibility, digestion and postprandial metabolism. British Journal of Nutrition, 116(5), 816-833. https:// doi.org/10.1017/S0007114516002610

Guraya, H.S., James, C. and Champagne, E.T. (2001). Effect of enzyme concentration and storage temperature on the formation of slowly digestible starch from cooked debranched rice starch. StarchStärke, 53(3-4), 131-139. https:// doi.org/10.1002/1521-379X(200104)

53:3/4<131::AID-STAR131>3.0.CO;2-M
Holm, J., Lundquist, I., Björck, I., Eliasson, A.C. and Asp, N.G. (1988). Degree of starch gelatinization, digestion rate of starch in vitro, and metabolic response in rats. American Journal of Clinical Nutrition, 47(6), 1010-1016. https://doi.org/10.1093/ ajcn/47.6.1010

Huang, R., Pan, X., Lv, J., Zhong, W., Yan, F., Duan, F. and Jia, L. (2018). Effects of explosion puffing on the nutritional composition and digestibility of grains. International Journal of Food Properties, 21 (1), 2193-2204. https:// doi.org/10.1080/10942912.2018.1514634

Izydorczyk, M. (2005). Understanding the Chemistry of Food Carbohydrates. In Cui, S.W. (Ed.), Food Carbohydrates. Taylor and Francis, Singapore. https://doi.org/10.1201/9780203485286.ch1

Jaspreet, S., Anne, D. and Lovedeep, K. (2010). Starch digestibility in food matrix: a review. Trends in Food Science and Technology, 21(4), 168-180. https:// doi.org/10.1016/j.tifs.2009.12.001

Lazou, A., Krokida, M. and Tzia, C. (2010). Sensory properties and acceptability of corn and lentil extruded puffs. Journal of Sensory Studies, 25(6), $838-860$. https://doi.org/10.1111/j.1745459X.2010.00308.X

Marabi, A. and Saguy, I.S. (2004). Effect of porosity on rehydration of dry food particulates. Journal of the Science of Food and Agriculture, 84(10), 11051110. https://doi.org/10.1002/jsfa.1793

Miao, M., Jiang, B., Cui, S.W., Zhang, T. and Jin, Z. (2015). Slowly Digestible Starch-A Review. Critical Reviews in Food Science and Nutrition, 55 (12), $1642-1657$. https:// doi.org/10.1080/10408398.2012.704434

Nurdjanah, S., Yuliana, N., Astuti, S., Hernanto, J. and Zukryandry, Z. (2017). Physico Chemical, Antioxidant and Pasting Properties of Pre-heated Purple Sweet Potato Flour. Journal of Food and Nutrition Sciences, 5(4), 140146. https://doi.org/10.11648/j.jfns.20170504.11

Oh, I.K., Bae, I.Y. and Lee, H.G. (2014). In vitro starch digestion and cake quality: Impact of the ratio of soluble and insoluble dietary fiber. International Journal of Biological Macromolecules, 63, 98-103. https://doi.org/https://doi.org/10.1016/ j.ijbiomac. 2013.10 .038

Rampersad, R., Badrie, N. and Comissiong, E. (2003). Physico-chemical and sensory characteristics of flavored snacks from extruded cassava/pigeonpea flour. Journal of Food Science, 68(1), 363-367. https://doi.org/10.1111/j.1365-2621.2003.tb14166.x

Rapp, E., Öström, Å., Bosander, F. and Gustafsson, I. 
(2007). The sensory effect of butter in culinary sauces. Journal of Foodservice, 18(1), 31-42. https://doi.org/10.1111/j.1745-4506.2007.00044.x

Ratnayake, W.S. and Jackson, D.S. (2006). Gelatinization and solubility of corn starch during heating in excess water: new insights. Journal of Agricultural and Food Chemistry, 54, 3712-3716. https://doi.org/10.1021/jf0529114

Roder, N., Ellis, P.R. and Butterworth, P.J. (2005). Starch molecular and nutritional properties: a review. Advances in Molecular Medicine, 1(1), 5-14.

Slavin, J. (2004). Whole grains and human health. Nutrition Research Reviews, 17(1), 99-110. https:// doi.org/DOI: 10.1079/NRR200374

Snow, P. and O'Dea, K. (1981). Factors affecting the rate of hydrolysis of starch in food. American Journal of Clinical Nutrition, 34(12), 2721-2727. https://doi.org/10.1093/ajen/34.12.2721

Subroto, E., Indiarto, R., Marta, H. and Shalihah, S. (2019). Effect of heat - moisture treatment on functional and pasting properties of potato (Solanum tuberosum L. var. Granola) starch. Food Research, 3 (5), 469-476. https://doi.org/10.26656/fr.2017.3 (5). 110

Tensiska, Siti Setiasih, I., Suprijana, O., Ali Qosim, W. and Cahyana, Y. (2017). Glycemic and Satiety Index of Some Degree of Milling of Indonesian Adlay (Coix Lachryma-Jobi Var Ma-Yuen) Indigenous Genotype. International Journal of Science and Research, 6, 2029-2034. https://doi.org/10.21275/ ART20177572

Tester, R.F. and Sommerville, M.D. (2003). The effects of non-starch polysaccharides on the extent of gelatinisation, swelling and $\alpha$-amylase hydrolysis of maize and wheat starches. Food Hydrocolloids, 17 (1), 41-54. https://doi.org/https://doi.org/10.1016/ S0268-005X(02)00032-2

$\mathrm{Wu}, \mathrm{T} .-\mathrm{T}$. , Charles, A.L. and Huang, T.-C. (2007). Determination of the contents of the main biochemical compounds of Adlay (Coxi lachrymaljobi). Food Chemistry, 104(4), 1509-1515. https:// doi.org/https://doi.org/10.1016/

j.foodchem.2007.02.027

Yang, S., Peng, J., Lui, W.-B. and Lin, J. (2008). Effects of adlay species and rice flour ratio on the physicochemical properties and texture characteristic of adlay-based extrudates. Journal of Food Engineering, 84(3), 489-494. https://doi.org/https:// doi.org/10.1016/j.jfoodeng.2007.06.010

Zhang, G. and Hamaker, B.R. (2009). Slowly digestible starch: concept, mechanism, and proposed extended glycemic index. Critical Reviews in Food Science and Nutrition, 49(10), 852-867. https:// doi.org/10.1080/10408390903372466 